$6.3(2-11)$ days. Average weight gain was $14.5 \mathrm{~g} / \mathrm{kg} /$ day for E1 and $17.8 \mathrm{~g} / \mathrm{kg} /$ day for E2 cohort $(\mathrm{p}<0.05)$. No patients in either epoch had necrotising enterocolitis.

Conclusions We demonstrate that feeding regime standardisation results in better early weight gain. The latter has been associated with improved long-term motor and cognitive development, as shown by Franz et al in 2009. Our sample size prohibits further conclusions. More studies including larger numbers are warranted.

\section{MASSAGE THERAPY BY MOTHER OR NURSE: EFFECT ON WEIGHT GAIN OF PREMATURE INFANTS}

doi:10.1136/archdischild-2012-302724.1395

Z Badiee, S Samsamshariat. Isfahan University of Medical Sciences, Isfahan, Iran

Introduction Since the introduction of surfactant the survival rate of preterm infants increased significantly. This has brought the expert's attention to maximizing the growth and development of this fragile population. Many studies demonstrated that massage has some roles in the weight gain of preterm infants. Our aim is to compare the effect of massage therapy among those who were massaged by a nurse or mother or none.

Method Our randomized clinical trial has three groups;

1. The infants who only received routine care and no massage,

2. those who received massage by an expert nurse and

3. and those who received massage by their mothers.

We recorded daily weight gain, the length of stay and fluid intake. We used the Kriskal-wallis test and the SPSS software.

Results The gestational age ranged between 28 to 34 weeks. At the end of the fifth day the group who were massaged by a nurse had significantly more weight gain compared to the other two groups. With $6.5+1.5$ for the nurse group, $1+4.6$ for the mother group and $1.5+3.7$ for the control group, P-value $=0.001$. Those who were massaged by their mother had gained significantly more than the control group P-value $=0.05$. there was no significant difference in the length of hospital stay among groups.

Discussion Our study shows that the five days massage therapy is a safe procedure for stable preterm infants to facilitate their weight gain. Mothers can perform this procedure. However more studies are needed to increase the efficacy of their performance.

\section{CAN EARLY PARENTERAL LIPID AND HIGH DOSE AMINO ACID ADMINISTRATION IMPROVE GROWTH IN VLBW INFANTS?}

doi:10.1136/archdischild-2012-302724.1396

${ }^{1} \mathrm{H}$ Vlaardingerbroek, 'D Rook, ${ }^{2} \mathrm{CHP}$ van den Akker, ${ }^{1} \mathrm{MJ}$ Vermeulen, ${ }^{3,4} \mathrm{JB}$ van Goudoever. 'Pediatrics, Division of Neonatology; 2 Pediatrics, Erasmus MC - Sophia Children's Hospital, Rotterdam; ${ }^{3}$ Pediatrics, Academic Medical Center - Emma Children's Hospital; ${ }^{4}$ Pediatrics, VU University Medical Center, Amsterdam, The Netherlands

Introduction The beneficial effects of early nutrition in preterm infants are well known. Nonetheless, almost all very low birth weight (VLBW; BW < 1500g) infants develop a protein and energy deficit in the first week of life and are growth impaired at discharged home.

We hypothesized that early parenteral lipid and high dose amino acid (AA) administration from birth onwards to VLBW infants is safe and increases growth.

Methods Inborn VLBW infants were randomized to one of three different parenteral nutritional regimens within 6hrs after birth (Figure).

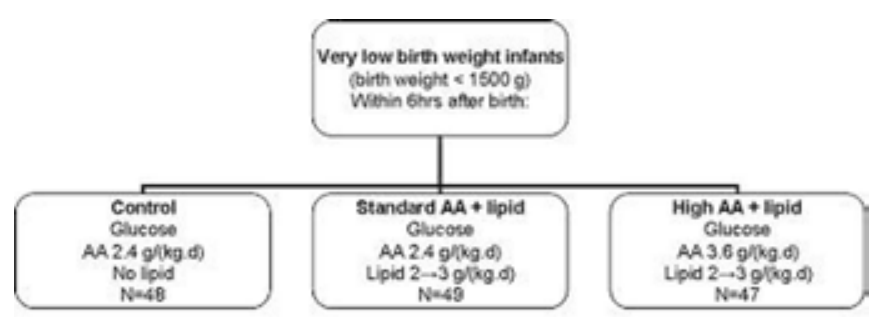

Abstract 1396 Figure 1 Study design

Growth rates during the first 28 days of life and during total hospital stay were calculated and the incidence of common neonatal morbidities (e.g., BPD, PDA, NEC, sepsis, IVH, ROP) was recorded. Results Growth was not significantly different between groups (Table; mean \pm SD). Mortality and the incidence of common neonatal morbidities were not significantly different between groups.

Abstract 1396 Table 1 Growth rates

\begin{tabular}{lccc}
\hline & Control & Standard AA + lipid & High AA + lipid \\
\hline Regain birth weight $(\mathrm{d})$ & $8 \pm 4$ & $8 \pm 4$ & $9 \pm 6$ \\
Weight gain first 28 days $(\mathrm{g} /(\mathrm{kg} . \mathrm{d}))$ & $12.9 \pm 5.5$ & $12.9 \pm 5.0$ & $12.5 \pm 5.9$ \\
$\begin{array}{l}\text { Head circumference gain first 28 days } \\
\text { (mm/wk) }\end{array}$ & $6.6 \pm 3.7$ & $5.6 \pm 2.8$ & $5.9 \pm 2.4$ \\
$\begin{array}{l}\text { Weight gain until discharge home }(\mathrm{g} / \\
(\mathrm{kg} . \mathrm{d}))\end{array}$ & $26.7 \pm 9.5$ & $24.9 \pm 5.4$ & $27.3 \pm 6.6$ \\
\hline
\end{tabular}

Conclusion Introduction of $2 \mathrm{~g}$ lipids/(kgd) and $3.6 \mathrm{~g} \mathrm{AA} /(\mathrm{kg} \cdot \mathrm{d})$ from birth onwards seems safe and does not affect the incidence of common neonatal morbidities. Growth was not improved by increasing amino acid or lipid intake in first few days of life.

\section{WEIGHT GAIN (WG) AND SODIUM MONITORING IN VLBW INFANTS (VLBWI) FED DONOR HUMAN MILK (DM+) VERSUS NO DONOR MILK (DM-)}

doi:10.1136/archdischild-2012-302724.1397

${ }^{1} \mathrm{KA}$ Marinelli, ${ }^{2} \mathrm{MM}$ Lussier, ${ }^{3} \mathrm{Jl}$ Hagadorn. ${ }^{1}$ Neonatology and Human Lactation, Connecticut Children's Medical Center and University CT School of Medicine; '2Lactation, Connecticut Children's Medical Center; ${ }^{3}$ Neonatology, Connecticut Children's Medical Center and University CT School of Medicine, Hartford, CT, USA

Background and Aims The impact of supplementing mother's milk (MM) with donor milk (DM) upon VLBWI WG and serum $\mathrm{Na}$ $(\mathrm{sNa})$ is unclear. This study aimed to compare WG, lowest $\mathrm{sNa}$ (LowNa), and number of sNa samples ( $\mathrm{NumNa}$ ) between birth and 56 days in DM+ versus DM- VLBWI.

Methods Single-center clinical/nutritional data, weekly weights and all sNa during the first 56 days were collected between 10/20099/2011 for inborn VLBWI still hospitalized at 28 days. DM was tested for association with WG, Low Na, and $\mathrm{NumNa}$.

Results 95 VLBWI were studied, with GA $28.4 \pm 2.8$ weeks, BWt $1031 \pm 295$ grams, 29 (31\%) DM+. Median enteral intake in the first 28 days (EI28) was $1791 \mathrm{ml}$ (range 0-5882); among DM+, median DM intake (DMI28) was $787 \mathrm{ml}$ (range 76-2105). DM+ versus DMdid not differ in GA, BWt, gender, race, EI28, or days on ventilator, CPAP or parenteral nutrition in the first 28 days. At 56 days, overall median (IOR) WG was 1047 (902, 1192) gm/kg BWt, overall LowNa was $132(128.5,135) \mathrm{mEq} / \mathrm{L}$. NumNa was 19 (9.5, 37). In univariate analysis, $\mathrm{DM}+$ and $\mathrm{DM}$ - did not differ regarding $\mathrm{WG}$, Low Na, or NumNa (Table1). In multivariable linear mixed modeling DMI28 was associated with a statistically significant but trivial decrease in Low Na (Table2), and was not an independent determinant of WG or NumNa. 